\title{
Editoriali/Editorials
}

\section{The state of research on the mental health effects of terrorism}

\author{
CAROL S. NORTH and BETTY PFEFFERBAUM
}

\section{INTRODUCTION}

As national and international large-scale incidents of terrorism increasingly threaten populations around the world, understanding the mental health effects of terrorism becomes a pressing need. Terrorism is fueled by the potential psychological effects it is intended to exert on populations. If the population is terrorized, intimidated, demoralized, and immobilized, then terrorism has succeeded. Understanding and responding to these psychological effects of terrorism may help dismantle the power of terrorist attacks. In approaching the study of mental health effects of terrorism, it is important to examine different exposure groups separately. These groups comprise 1) those directly exposed to the event, such as people who were in the Murrah Building in Oklahoma City when the bomb detonated; 2) those indirectly exposed, such as residents of the community not present at the disaster site but whose lives were disrupted by, for example, interrupted access to their residences or loss of their job sites; and 3) remotely affected populations, such as residents of other cities in the same region or the same country. There are other relevant disaster-exposed subpopulations as well, such as rescue workers and bereaved family and friends of those killed in terrorist incidents, who also deserve separate consideration because they may have special issues, such as a history of alcohol abuse or dependence in professional firefighters (North et al.,

Address for correspondence: C.S. North, Department of Psychiatry, Washington University School of Medicine, 660 S. Euclid, Campus Box 8134, St. Louis, MO 63110 (USA).

Fax: $314-747-2140$

E-mail: northc@psychiatry.wustl.edu

Declaration of Interest: this research was supported by National Institute of Mental Health Grant MH66628 to Dr. North.
$2002 \mathrm{~b}$ ) and grief issues among the bereaved. The important issues of these populations, however, are beyond the scope of the arguments to be made here. The discussion to follow will consider the three main exposure groups separately in critically examining the relevant research literature.

\section{POSTTRAUMATIC STRESS DISORDER IN POPULATIONS DIRECTLY EXPOSED TO MAJOR TERRORIST INCIDENTS}

Few studies of terrorism have addressed the prevalence or course of posttraumatic stress disorder (PTSD) in citizen populations directly exposed to major terrorist incidents (Gidron, 2002). Table I summarizes the published literature on studies of PTSD in directly exposed survivors of terrorist incidents. These terrorist incidents have included bombings, bus attacks, and mass shootings. Two of the terrorist incidents reviewed in table I occurred within the United States, a mass shooting episode in New York and the Oklahoma City bombing. The advent of large scale terrorism within the United States and its accelerating pace over the last decade have created a sense of urgency to develop a research base that can guide mental health interventions following large scale terrorism.

Methodological inconsistencies across research studies on mental health effects of terrorism preclude comparison of findings from one event to the next. The studies listed in table I employed an assortment of research methods, including for the assessment of psychiatric diagnosis. Despite reporting specific rates of PTSD, most studies did not apply full diagnostic criteria (Amir et al., 1998; North et al., 1999). The only terrorist incident in table I studied with a structured, full diagnostic assess- 
The state of research on the mental health effects of terrorism

Table I. - PTSD in directly exposed survivors of terrorism.

\begin{tabular}{|c|c|c|c|}
\hline Author & Study sample & Instruments & PTSD rate (timing) \\
\hline Curran et al., 1990 & $\begin{array}{l}26 \text { survivors of the November } 1987 \\
\text { Enniskillen bombing in Northern Ireland }\end{array}$ & $\begin{array}{l}\text { Clinical diagnosis and DSM-III-R } \\
\text { symptom schedule }\end{array}$ & $50 \%$ (6 mos post $)$ \\
\hline Abenhaim, 1992 & $\begin{array}{l}254 \text { survivors of } 21 \text { terrorist attacks } \\
\text { in France }\end{array}$ & $\begin{array}{l}\text { Self-report DSM-III-based } \\
\text { symptom questionnaires }\end{array}$ & $\begin{array}{l}18 \% \text { (approx } 4-5 \text { yrs post) } \\
\text { ( } 11 \% \text { in uninjured, } 31 \%, \\
\text { in injured) }\end{array}$ \\
\hline Shalev, 1992 & $\begin{array}{l}12 \text { Israeli survivors of terrorist attack } \\
\text { on a civilian bus }\end{array}$ & DSM-III-R PTSD symptom checklist & $33 \%(8-10$ mos post $)$ \\
\hline Trappler \& Friedman, 1996 & $\begin{array}{l}11 \text { survivors of shooting incident against } \\
\text { Hasidic Jews in NY }\end{array}$ & $\begin{array}{l}\text { DSM-IV PTSD symptom scale and } \\
\text { clinical evaluation }\end{array}$ & $36 \%(2 \operatorname{mos}$ post $)$ \\
\hline Amir et al., 1998 & $\begin{array}{l}15 \text { uninjured Israeli women surviving } \\
\text { bus bombing }\end{array}$ & DSM-III-R PTSD symptom scale & $27 \%$ (6 mos post) \\
\hline North et al., 1999 & $\begin{array}{l}182 \text { adult survivors of the Oklahoma } \\
\text { city bombing }\end{array}$ & DIS-III-R & $34 \%$ (6 mos post) \\
\hline $\begin{array}{l}\text { Centers for } \\
\text { Disease Control, } 2002\end{array}$ & $\begin{array}{l}244 \text { staff of school } 2 \text { blocks from WTC } \\
\text { on } 9 / 11 \text { ( } 30-50 \% \text { witnessed plane } \\
\text { crashes / building collapse; } 30-40 \% \\
\text { knew individuals in the attacks) }\end{array}$ & $\begin{array}{l}\text { Veteran's Administration } \\
\text { PTSD checklist }\end{array}$ & $\begin{array}{l}23 \% \text { met PTSD symptom } \\
\text { criteria ( } 4 \text { mos post) }\end{array}$ \\
\hline
\end{tabular}

ment for PTSD was the Oklahoma City bombing (North et al., 1999). In that study, $34 \%$ of the directly exposed bombing survivors were diagnosed with PTSD in the 6month postbombing period. Despite the variety of diagnostic methods applied, the other studies of terrorist events identified in table I reported similar rates of PTSD (Curran et al., 1990), identifying the diagnosis in approximately one-fourth to one-half of directly exposed survivors following these major terrorist events.

Intentionally perpetrated acts such as terrorism are thought to have more severe mental health consequences on survivors than natural disasters and technological accidents (Baum et al., 1983), presumably related to the heinous intent behind the incident. From the available data, however, it is not universally agreed that the most severe mental health effects of disasters are associated with terrorist events (Rubonis \& Bickman, 1991). The difficulty of determining the relative psychological effects of terrorism compared to natural disasters or technological accidents is that the different events studied may not be equivalent in scope and magnitude. The severity of terrorist events such as the Oklahoma City bombing and the September 11,2001, terrorist attacks, for example, as measured by sheer scope, magnitude, and horror may be the major determinant of mental health consequences, not the distinguishing intentional nature of terrorist acts. To determine whether terrorism produces greater psychological effects than other kinds of disasters will require comparison of survivors of several disasters of different types that vary in scope and magnitude, using the same methodology and instruments, and controlling for disaster-specific variables in the analyses.

Because terrorism is intentionally perpetrated for the express purpose of evoking fear and intimidating the population (Pfefferbaum et al., 2002), the main goal is not the physical damage to people targeted by terrorism but the psychological effects on the wider society. The societal-wide threat posed by terrorism may evoke emotional distress among community members not directly targeted for physical injury, an effect not observed in relation to natural disasters and accidental catastrophes. This aspect of terrorism requires population studies of mental health effects in affected communities to fully appreciate the wide toll of these events.

Disaster research predating the April 19, 1995, bombing of the Murrah Federal Building in Oklahoma City focused on the most directly exposed groups, occasionally reporting psychiatric findings in indirectly exposed or remotely affected groups for purposes of comparison by exposure dose. After the Oklahoma City bombing and the September 11, 2001, terrorist attacks, however, research attention shifted to indirectly exposed and remotely affected population samples. Research efforts were redirected to the far-reaching effects of terrorism on the psychological wellbeing of the population. 


\section{STUDIES OF INDIRECTLY EXPOSED COMMUNITY POPULATIONS TO MAJOR TERRORIST INCIDENTS}

Research on the mental health effects in affected populations not directly or vicariously exposed to disasters raises distinct issues from previous research focused on PTSD among the directly exposed survivors. By definition, PTSD cannot occur without the requisite exposure to the traumatic event. Exposures that qualify include direct physical contact with the disaster agent, witnessing the event, and vicarious exposure through the direct exposure of a loved one to the disaster agent. Large-scale terrorism presents problems in demarcating the edges of the direct exposure and determining what constitutes witnessing. Although entire communities may feel threatened during and after terrorist events, this experience does not signify the immediate threat to life or limb experienced by those physically caught in an attack. Viewing the unfolding of a terrorist attack on television, even with live images in real time and repeated play of graphic images of horror, is also not the same experience as direct eyewitness of the event in person. Therefore, in communities victimized by terrorism, indirectly exposed individuals and those with exposure limited to media coverage cannot be considered candidates for PTSD. This point has been argued in more detail elsewhere (North $e t$ al., 2002a; North \& Pfefferbaum, 2002; Pfefferbaum et al., 1999a).

Bioterrorism presents even more difficult distinctions in defining exposure. Onset of physical damage following exposure to bioterrorism may be delayed or gradual, and physical effects may not be immediately perceptible. Determination of exposure to a bioterrorist incident may depend on laboratory testing, and some individuals potentially at risk may not learn of their exposure status until much later, if at all. Thus, psychological effects of bioterrorist incidents may correspond more to perceived exposure than to actual exposure to the agent. The population with perceived exposure will be expected to exceed many times over the numbers with actual exposure (Salter, 2001).

Table II. - Studies of indirectly exposed community populations to major terrorist incidents.

\begin{tabular}{|c|c|c|c|}
\hline Author & Study sample & Instruments & $\begin{array}{l}\text { Posttraumatic } \\
\text { findings (timing) }\end{array}$ \\
\hline Pfefferbaum et al., 1999a & $\begin{array}{l}3218 \text { Oklahoma City middle and } \\
\text { high school students surveyed } 7 \text { weeks } \\
\text { after the bombing of the Murrah Federal } \\
\text { Building }\end{array}$ & Inpact of Event Scale-Revised & $\begin{array}{l}\text { PTSD symptoms related to female } \\
\text { gender, interpersonal exposure, } \\
\text { and viewing television coverage }\end{array}$ \\
\hline
\end{tabular}

Galea et al., 2002 1008 adult residents of Manhattan; random-digit dial study

Schlenger et al., 2002

$\mathrm{N}=2,273$; adult population study of New York City, Washington DC, and other metro areas; web-based survey

Bleich et al., 2003

510 Israelis chronically exposed to terrorist acts in their communities (16\% personally exposed); telephone survey

Centers for Disease Control, 2002

Hoven, 2002

Stuber et al., 2002

\section{5 staff of school $>5$ miles from} WTC on $9 / 11$

8,2664 th-12th grade students in NYC public schools; school surveys
PTSD and depression symptom criteria derived from DIS questions

PTSD checklist; one or more sy mptoms endorsed in top 2 of 5 response categories

Stanford Acute Stress Reaction Questionnaire

Veteran's Administration PTSD checklist

Symptom questions from DISC predictive scales (DPS)

Symptoms of PTSD: $8 \%$ overall, $20 \%$ of those living near WTC; symptoms of depression: $10 \%$ (5-8 wks post)

"Probable PTSD" $11 \%$
NYC (1-2 mos post)

PTSD symptom criteria met by $9 \%$ (during exposure at 19 mos)

6\% met PTSD symptom criteria (4 mos post)

Probable psychiatric diagnoses: $29 \%$ any disorder, $15 \%$ agoraphobia, $12 \%$ social anxiety, $11 \%$ PTSD, $11 \%$ conduct disorder, $10 \%$ generalized anxiety, $9 \%$ panic, $8 \%$ major depression, $7 \%$ alcohol (6 mos post)

PTSD symptom criteria derived from DIS questions
$\mathrm{N}=112$ children in a study of 1,008 adult residents of Manhattan sampled by random-digit dialing, and their parents
Problems getting along with other children $(21 \%)$, concentrating or paying attention $(40 \%)$, or being unhappy or depressed $(31 \%)$. $16 \%$ of the children's parents had symptoms of PTSD (5-8 wks post). 
Another issue in the assessment of psychological effects of terrorism in general populations is the resource burden entailed in full diagnostic assessments on large population samples that are prohibitive for systematic research. With care in sampling, representative selection of a smaller group for full assessment can provide accurate estimates of the prevalence of disorders. Another approach is to use brief surveys of large population samples, which provide information about psychiatric symptoms and symptom clusters without fully assessing diagnostic criteria. The validity of symptoms without the context of full psychiatric assessment, however, is uncertain.

Table II summarizes research on posttraumatic responses to terrorism in indirectly exposed members of attacked communities. These studies are encumbered by the difficulties in defining exposure and its subsequent effects on interpreting of posttraumatic responses as described above. Most of these research studies sampled mixed exposure subgroups, including some individuals with direct exposure intermingled with the indirectly exposed respondents. Rates of symptoms fulfilling PTSD symptom criteria ranged from $8 \%$ to $16 \%$ in these indirectly exposed population samples. These measures of symptoms are difficult to interpret, however, in populations without the requisite exposure to the event for eliciting characteristic PTSD symptoms.

Further, studies may not have determined that the symptoms are new after the disaster or specifically pertain to it, or that they persisted for at least a month required for the diagnosis of PTSD. Additionally, the clinical significance of these symptoms is uncertain, because the effects on the individual's functioning associated them was not provided. Many so-called "symp- toms" if they do not impair functioning may actually reflect normative responses. These include, for example, heightened awareness or sensitivity to stimuli related to the disaster experience that tends to fade with time, responses expected in almost anyone exposed to a highly traumatic event. Further, diagnoses such as "agoraphobia" in the context of terrorism invite questions about the validity of the pathological basis of fear in the context of a major terrorist attack on one's community. Diagnoses such as conduct disorder raise further questions about pre-existing behavioral problems and the importance of separating incident or new postdisaster disorders from pre-existing psychopathology. Disorders present before an event cannot be ascribed to it.

\section{STUDIES OF POPULATIONS REMOTELY AFFECTED BY MAJOR TERRORIST INCIDENTS}

Table III summarizes research on national populations studied after large-scale terrorist incidents. These populations are considered remotely affected because their geographical distance from the terrorist site precludes any possible form of direct exposure or eyewitness to the event, disallowing diagnosis of PTSD in relation to the incident. Even more than in indirectly exposed populations, questions can be raised about alleged posttraumatic symptoms not anchored to a traumatic event and without the requisite exposure to a qualifying precipitating event for eliciting symptoms. The failure of these studies to attach symptoms to a qualifying exposure is furiher complicated by failure to note the timing of symptoms, whether they were new after the event or had pre-existed,

Table III. - Studies of populations remotely affected by major terrorist incidents.

\begin{tabular}{|c|c|c|c|}
\hline Author & Study sample & Instruments & PTSD rate (timing) \\
\hline Schuster et al., 2001 & $\begin{array}{l}560 \text { representative US adults; } \\
\text { random-digit dial study }\end{array}$ & $\begin{array}{l}\text { PTSD symptoms ( } 5 \text { most prevalent } \\
\text { from Oklahoma City bombing study) }\end{array}$ & $\begin{array}{l}\text { PTSD symptoms: "substantial" } \\
44 \% \text {; any, } 90 \% \text { (3-5 days post) }\end{array}$ \\
\hline Schlenger et al., 2002 & $\begin{array}{l}\mathrm{N}=2,273 \text {; adult population study } \\
\text { of New York City, Washington DC, } \\
\text { and other metro areas; } \\
\text { web-based survey }\end{array}$ & $\begin{array}{l}\text { PTSD checklist; } \\
\text { one or more symptoms } \\
\text { endorsed in top } 2 \text { of } 5 \text { response } \\
\text { categories }\end{array}$ & $\begin{array}{l}\text { "Probable PTSD" } 3 \% \\
\text { Washington, DC; } 4 \% \text { other } \\
\text { metro areas (1-2 mos post) }\end{array}$ \\
\hline Silver et al., 2002 & $\begin{array}{l}\mathrm{N}=2,729 ; \text { US adult population } \\
\text { sample outside New York City; } \\
\text { web-based survey }\end{array}$ & Impact of Events Scale-Revised & $\begin{array}{l}\text { Moderately distressing PTSD } \\
\text { symptoms: } 17 \% \text { ( } 1-2 \text { mos } \\
\text { post), } 6 \% \text { ( } 6 \text { mos post) }\end{array}$ \\
\hline Pfefferbaum et al., 2000 & $\begin{array}{l}696 \text { th graders within } 100 \text { miles } \\
\text { of the Oklahoma City bombing }\end{array}$ & Impact of Event Scale-Revised & $\begin{array}{l}\text { Media exposure, indirect } \\
\text { interpersonal exposure, and } \\
\text { functional difficulties were } \\
\text { related to PTSD symptom } \\
\text { endorsement in children living } \\
100 \text { miles from Oklahoma City } \\
\text { (2 years post) }\end{array}$ \\
\hline
\end{tabular}


making it unlikely that they could be ascribed to the event. The PTSD diagnosis in these studies may include cases related to a variety of traumatic events, not just the disaster in question, therefore explaining a portion of the cases reported.

The rates of PTSD symptoms and diagnostic estimates among the studies summarized in table III are scattered in numbers reported. The scatter in rates of posttraumatic symptoms assessed in remotely affected populations suggests the symptoms identified may be part of the statistical "noise" inherent in the methodological imprecision of the data acquired.

\section{STUDIES OF CHILDREN AND TERRORISM}

Most studies of children's reactions to terrorism have investigated children indirectly exposed or remotely affected though some studies have used samples in which directly exposed children were intermingled. Studies of children, like those of adults, have typically focused on posttraumatic stress reactions as an outcome despite failure to establish the requisite exposure. For example, Pfefferbaum et al. (1999b; 2000) surveyed school children with a range of exposure to the Oklahoma City bombing yet treated the outcome measure similarly without fully considering the exposure criterion. In the largest study of the impact of terrorism on children to date, Hoven (2002) used a psychiatric screening instrument to examine a representative sample of over 8,000 New York City school children six months after the September 11 attacks. An estimated $11 \%$ of children developed symptoms consistent with PTSD and more than one-fourth had at least one of the mental health problems assessed. Unfortunately, the rigor in establishing diagnoses in this study is unclear as is the temporal relationship of disorders to the attacks. Other studies have used parent report, notable for underestimating distress in their children (Earls et al., 1988; Handford et al., 1986), to describe children's reactions to the September 11 attacks (Schlenger et al., 2002; Schuster et al., 2001; Stuber et al., 2002). Thus studies of children's reactions to terrorism are even more problematic than those of adults.

\section{DISCUSSION}

To fully understand the mental health effects of terrorism, it is imperative to examine the most highly exposed groups and compare them from one incident to another using similar methodology and instruments, and to con- trast different exposure groups (directly exposed, indirectly exposed, remotely affected) from the same terrorist incident. Much of the research on terrorism has not sorted out these subpopulations.

Research on PTSD in directly exposed populations following different terrorist attacks has found that between one-fourth to one-half of directly exposed survivors can be expected to develop PTSD based on studies of terrorist attacks conducted in Ireland, France, Israel, and the United States. Given the array of methods used in these studies and the range of variables relating to severity, magnitude, and exposure level in the various disasters studied, it is surprising that the spread of reported PTSD rates was not wider.

Comparisons of the mental health effects of terrorism in different exposure subgroups from the same events await data not available at present. Comparing PTSD in populations directly exposed to terrorism with indirectly exposed groups is problematic because the indirectly exposed group by definition lacks the exposure required to produce associated symptoms. This exercise presents a logical challenge: How does one examine posttraumatic symptoms in affected populations without traumatic exposure? The answer is that this emotional response or distress does not constitute PTSD, and symptoms cannot be ascribed to a traumatic origin in the absence of the requisite traumatic event. Nonassignment of a PTSD label, whether a diagnosis of PTSD or recognition of PTSD symptoms, to posttraumatic emotional responses is not intended to discount the significance of the indirect exposure and its associated distress. Emotional distress not meeting diagnostic criteria for PTSD deserves mental health attention, although interventions may differ from those provided to directly exposed individuals with PTSD.

A challenge in mental health assessment of individuals and populations indirectly exposed to and remotely affected by terrorism is to refrain from assumptions of causality in interpretation of symptoms and disorders observed after disasters. Interventions assuming postdisaster difficulties to originate with traumatic experience may provide a disservice to individuals with pre-existing difficulties, although interventions for such problems need to consider the context or effects of the traumatic event in the course of events.

In comparing mental health effects of terrorist events with one another, it is imperative to compare groups by exposure type. For example, the North et al. (1999) study of the Oklahoma City bombing examined only directly exposed survivors, finding a $34 \%$ incidence of PTSD in association with the event. The Galea et al. 
(2002) study of the September 11 th terrorist attacks on New York City, however, examined a mixed sample of indirectly exposed and remotely affected individuals from the area with some directly exposed individuals intermingled, finding an overall $8 \%$ rate of probable PTSD cases. Psychiatric effects of the directly exposed survivors of the Oklahoma City bombing are not comparable to those among the population of Manhattan sampled after New York City's September 11 th attacks, as reflected in the very different rates of PTSD reported. This disparity in reported rates demonstrates the importance of considering exposure subgroups separately in estimating mental health effects of terrorist events and planning interventions tailored to the population's need.

\section{REFERENCES}

Abenhaim L. (1992). Study of civilian victims of terrorist attacks (France 1982-1987). Journal of Clinical Epidemiology 45, 103-109.

Amir M., Weil G., Kaplan Z., Tocker T. \& Witztum E. (1998). Debriefing with brief group psychotherapy in a homogenous group of non-injured victims of a terrorist attack: a prospective study. Acta Psychiatrica Scandinavica 98, 237-242.

Baum A., Fleming R. \& Davidson L. M. (1983). Natural disaster and technological catastrophe. Environment and Behavior 15, 333-354.

Bleich A., Gelkopf M. \& Solomon Z. (2003). Exposure to terrorism, stress-related mental health symptoms, and coping behaviors among a nationally representative sample in Israel. Journal of the American Medical Association 209, 612-620.

Centers for Disease Control (2002). Impact of September 11 attacks on workers in the vicinity of the World Trade Center--New York City. Morbidity and Mortality Weekly Report 51, 8-10.

Curran P.S., Bell P., Murray A., Loughrey G., Roddy R. \& Rocke L.G. (1990). Psychological consequences of the Enniskillen bombing. British Journal of Psychiatry 156, 479-482.

Earls F., Smith E., Reich W. \& Jung K.G. (1988). Investigating psychopathological consequences of a disaster in children: a pilot study incorporating a structured diagnostic interview. Journal of the American Academy of Child and Adolescent Psychiatry 27, 90-95.

Galea S., Ahern J., Resnick H., Kilpatrick D., Bucuvalis M., Gold J. \& Vlahov D. (2002). Psychological sequelae of the September 11 terrorist attacks in New York City. New England Journal of Medicine 346, 982-987.

Gidron Y. (2002). Posttraumatic stress disorder after terrorist attacks: a review. Journal of Nervous and Mental Disease 190, 118-121.

Handford H.A., Mayes S.D., Mattision R.E., Humphrey F.J., Bagnato S., Bixler E.O. \& Kales J.D. (1986). Child and parent reaction to the Three Mile Island nuclear accident. Journal of the American Academy of Child and Adolescent Psychiatry 25, 346-356.

Hoven C.W. (2002). Testimony Regarding Unmet Mental Health Needs of New York City Public School Children as a Result of the September Ilth attacks on the World Trade Center. US Senate Health, Education, Labor and Pensions (HELP) Committee.

North C.S. \& Pfefferbaum B. (2002). Research on the mental health effects of terrorism. Journal of the American Medical Association 288, 633-636.

North C.S., Nixon S.J., Shariat S., Mallonee S., McMillen J.C., Spitznagel E.L. \& Smith E.M. (1999). Psychiatric disorders among survivors of the Oklahoma City bombing. Journal of the American Medical Association 282, 755-762.

North C.S., Pfefferbaum B. \& Tucker P. (2002a). Ethical and methodological issues in academic mental health research in populations affected by disasters: the Oklahoma City experience relevant to September 11, 2001. CNS Spectrum 7, 580-584.

North C.S., Tivis L., McMillen J.C., Pfefferbaum B., Spitznagel E.L., Cox J., Nixon S., Bunch K.P. \& Smith E.M. (2002b). Psychiatric disorders in rescue workers after the Oklahoma City bombing. American Journal of Psychiatry 159, 857-859.

Pfefferbaum B., Nixon S.J., Krug R.S., Tivis R.D., Moore V.L., Brown R.M., Pynoos R.S., Foy D. \& Gurwitch R.H. (1999a). Clinical needs assessment of middle and high school students following the 1995 Oklahoma City bombing. American Journal of Psychiatry 156 , 1069-1074.

Pfefferbaum B., Nixon S.J., Tivis R.D., Doughty D.E., Pynoos R.S., Gurwitch R.H. \& Foy D.W. (1999b). Television exposure in children after a terrorist incident. Psychiatry 64, 202-211.

Pfefferbaum B., Seale T.W., McDonald N.B., Brandt E.N., Rainwater S.M., Maynard B.T., Meierhoefer B. \& Miller P.D. (2000). Posttraumatic stress two years after the Oklahoma City bombing in youths geographically distant from the explosion. Psychiatry 63, 358-370.

Pfefferbaum B., Pfefferbaum R.L., North C.S. \& Neas B.R. (2002). Does television viewing satisfy criteria for exposure in posttraumatic stress disorder? Psychiatry 65, 306-309.

Rubonis A.V. \& Bickman L. (1991). Psychological impairment in the wake of disaster: the disaster-psychopathology relationship. Psychological Bulletin 109, 384-399.

Salter C.A. (2001). Psychological effects of nuclear and radiological warfare. Military Medicine 166, 17-18.

Schlenger W.E., Caddell J.M., Ebert L., Jordan B.K., Rourke K.M., Wilson D., Thalji L., Dennis J.M., Fairbank J.A. \& Kulka R.A. (2002). Psychological reactions to terrorist attacks: findings from the National Study of Americans' Reactions to September 11. Journal of the American Medical Association 288, 581-588.

Schuster M.A., Stein B.D., Jaycox L., Collins R.L., Marshall G.N., Elliott M.N., Zhou A.J., Kanouse D.E., Morrison J.L. \& Berry S.H. (2001). A national survey of stress reactions after the September 11, 2001, terrorist attacks. New England Journal of Medicine 345, 1507-1512.

Shalev A.Y. (1992). Posttraumatic stress disorder among injured survivors of a terrorist attack. Predictive value of early intrusion and avoidance symptoms. Journal of Nervous and Mental Disease 180 , 505-509.

Silver R.C., Holman E.A., McIntosh D.N., Poulin M. \& Gil-Rivas V. (2002). Nationwide longitudinal study of psychological responses to September 11. Journal of the American Medical Association 288, 1235-1244.

Stuber J., Fairbrother G., Galea S., Pfefferbaum B., Wilson-Genderson M. \& Vlahov D. (2002). Determinants of counseling for children in Manhattan after the September 11 attacks. Psychiatric Services 53, 815-822.

Trappler B. \& Friedman S. (1996). Posttraumatic stress disorder in survivors of the Brooklyn Bridge shooting. American Journal of Psychiatry 153, 705-707. 